\title{
Influence of grid orientation and time of day on grid sorting in a small-meshed trawl fishery for Norway pout (Trisopterus esmarkii)
}

\author{
Ole Ritzau EIGAARD ${ }^{\mathrm{a}}$, Bent HERRMANN and J. Rasmus NIELSEN
}

Technical University of Denmark, National Institute of Aquatic Resources (DTU-Aqua), Section for Management Systems, Charlottenlund Castle, 2920 Charlottenlund, Denmark

Received 4 January 2011; Accepted 4 November 2011

\begin{abstract}
A lightweight sorting grid was developed to reduce bycatch in the Danish small-meshed trawl fishery (22 $\mathrm{mm}$ full mesh in the cod end) for Norway pout in the North Sea. Experimental fishing with the grid demonstrated the possibility to capture Norway pout with only a minimum of unintended bycatch. Fishing with two different grid orientations, backwards and forwards-leaning, in distinct day and night hauls, resulted in an estimated release of between 88.4 and $100 \%$ of the total number of haddock (Melanogrammus aeglefinus) and whiting (Merlangius merlangus) entering the trawl. However, bycatch reductions were not significantly different between day and night or between grid orientations, indicating that the grid rejection of haddock and whiting is not influenced by fish behaviour. The loss of the target species, Norway pout, was low (between $5.6 \%$ and $13.7 \%$ ) in comparison with the bycatch excluded, and clearly length dependent. Consequently, loss of target species would vary with the size structure of the population fished. Although results were not statistically significant, length-based analyses indicated that the grid rejection likelihood for particularly smaller Norway pout $(<16 \mathrm{~cm})$ was higher when fishing with the forwards-leaning grid during the night; this might be explained by behavioural and visual aspects of the fish-grid encounter process for Norway pout.
\end{abstract}

Key words: Bycatch reduction/Gear selectivity / Bootstrap method/Discard/Fish behaviour/Diurnal effects / Gadidae / Norway pout / North Sea

\section{Introduction}

Norway pout is an important prey species for other larger gadoids such as cod (Gadus morhua), haddock, whiting and saithe (Pollachius virens) and has an overlapping distribution with these species in the North Sea and Skagerrak area (Sparholt et al. 2002a, 2002b; Lambert et al. 2009). Norway pout is also the target species of a small-meshed North Sea trawl fishery (typically $22 \mathrm{~mm}$ full mesh in the cod end), which has almost exclusively involved large trawlers from Denmark ( 70-80\% of yearly landings) and Norway ( 20-30\% of yearly landings) over the last ten years. The main seasons are $3 \mathrm{rd}$ and 4 th quarters of the year and the main North Sea fishing areas are Fladen Ground and the edge of the Norwegian Trench. Norway pout is landed for reduction purposes (fish meal and fish oil) and fishing is carried out with relatively large vessels and trawls,

\footnotetext{
a Corresponding author: ore@aqua.dtu.dk
}

resulting in typically large catch weights (up to 100 tonnes in the cod end). From 2000 to 2010, the average yearly landings from the North Sea and Skagerrak were approx. 70000 tonnes (t), fluctuating between $11345 \mathrm{t}$ and $196085 \mathrm{t}$. The years 2005 and 2007 are not included in this average, as the TAC was set at $0 \mathrm{t}$ owing to poor stock levels (ICES 2011). Historically, the economic and ecological sustainability of the Norway pout fishery in the North Sea has often been under pressure in terms of high variability in resource availability and occasional high levels of unintended bycatch, mainly of other gadoids. Bycatches of cod, haddock, whiting and saithe have been of particular concern to fisheries management (ICES 2011).

In an ecosystem-based approach to fisheries management, as formulated in the common fisheries policy (EU 2011), ecosystem sustainability of fisheries in relation to bycatch and discards is generally emphasized (e.g., Greenstreet and Rogers 2000; Lewinson et al. 2004; Tserpes et al. 2006). A number of EU Council and EU-Norway bilateral bycatch regulations have 
been introduced to make the Norway pout fishery more sustainable in terms of protecting vulnerable and heavily exploited species and size groups (see stock annex to ICES 2007 for a detailed description). Additional measures have also been suggested for this fishery, particularly the introduction of sorting grids. Previous studies have shown that metal sorting grids are capable of substantial bycatch reduction in the fishery (Eigaard and Holst 2004; Kvalsvik et al. 2006) and, although they were highlighted at ICES $(2007,2011)$, sorting grids have not yet become mandatory in the fishery. However, these previous experiments also demonstrated that large and heavy metal grids were difficult to handle in practical fishery use, thus becoming a detriment to catching performance and trawl durability and a hazard to crew safety. Consequently, the industry has been reluctant to put these grids into use, and the need for further grid development and testing in collaboration with the industry seemed obvious.

\section{Objectives}

In the present investigation, the objective was to develop and test a sorting grid for the Danish Norway pout fishery by combining the selective properties demonstrated for metal grids in this fishery with the handling advantages of grids made from synthetic materials used in other trawl fisheries (e.g., Madsen and Hansen 2001; Grimaldo and Larsen 2005; Loaec et al. 2006). Furthermore, grid orientation (backwards- or forwardsleaning) and time of day (day or night) were examined to establish whether these factors have a significant influence on grid sorting. Based on previous findings, showing that behavioural differences in the aft end of a trawl can result in species-specific selectivity (Krag et al. 2009) and that gadoid trawl catches vary with time of day (Michaelsen et al. 1996; Johnsen and Iilende 2007), it was hypothesized that different grid orientations, in combination with distinct day and night fishing, might provide a means to optimize the sorting performance of a grid.

To take the results beyond the experimental situation and make them comparable with other grid selectivity results from test fishing on populations with a different size structure, an additional objective was to carry out length-based analyses of the catch data. In meeting this latter objective, it proved necessary to expand the traditional methodology for lengthbased analysis of trawl and grid selectivity. The very large catches obtained, in combination with an experimental population structure containing only a few length classes, led to a need for extensive sub sampling of the test hauls and a new methodological approach.

\section{Materials and methods}

\subsection{Grid design}

The choice of grid design and materials was mainly based on practical and scientific experiences with sorting grids for the shrimp (Pandalus borealis) fisheries in the North Sea and Barents Sea (Isaksen et al. 1992; Madsen and Hansen 2001; Grimaldo and Larsen 2005) and in the Gulf of Maine (Riedel and DeAlteris 1995). The continuous development of the sorting grids used in these fisheries, suggested that a grid with a nylon frame and glass fibre bars could fulfill the objectives of an easy-to-handle lightweight sorting grid for the Norway pout fishery. The industry, i.e., net manufacturers and skippers in the Norway pout fishery, participated in the survey of potential grid designs and materials, as well as in the final choice of design.

In the final grid design, the nylon bars of the frame had a circular cross section of $50 \mathrm{~mm}$ in diameter. To optimize water flow across the sorting grid, its bars were drop-shaped and made of glass fibre (Riedel and DeAlteris 1995), with a cross section of $8 \mathrm{~mm}$. A width of $8 \mathrm{~mm}$ was the smallest evaluated technically feasible, given the large forces and catch weights in the fishery. To accommodate fitting the grid to the net drums of the vessel it was constructed in three flexible sections that were lashed to each other with nylon rope. Each section was $600 \mathrm{~mm}$ $\times 1300 \mathrm{~mm}$ resulting in overall grid dimensions of $1800 \times 1300$ mm (Fig. 1).

Based on fish length data from the ICES (International Council for Exploration of the Sea) International Bottom Trawl Survey (IBTS) and two earlier experiments with Norway pout sorting grids in the North Sea (Eigaard and Holst 2004; Kvalsvik et al. 2006), a bar distance of $23 \mathrm{~mm}$ was chosen. This distance lies in-between the two previously tested bar distances of $22 \mathrm{~mm}$ and $24 \mathrm{~mm}$, which have well documented selective properties, and was expected to offer the optimal trade off between maximizing release of unwanted bycatch and minimizing loss of target species.

\subsection{Experimental trawl and flume tank tests}

For the experimental fishery, a commercial butterfly trawl of 1150 meshes in circumference (120 mm full mesh) was made, with a specially designed four panel section built in $40 \mathrm{~mm}$ netting. The grid was mounted in this net section at an angle of 60 degrees from the horizontal, with the top of the grid pointing backwards from the trawl mouth. This resulted in a grid section with the fish outlet and the collecting bag ( $22 \mathrm{~mm}$ mesh) placed at the top of the section. Floats were attached to the top of the collecting bag to keep the outlet open during fishing (Fig. 2, top and Fig. 3). A guiding panel in $20 \mathrm{~mm}$ mesh was inserted in front of the grid leading all fish to encounter the grid at its lower section, a method that has been shown to improve sorting grid performance in the Norway pout fishery (Eigaard and Holst 2004; Kvalsvik et al. 2006).

For the experimental hauls with the forwards-leaning orientation of the grid, the four-seamed net section was simply turned up-side down (180 degrees). This resulted in a forwardsleaning grid with the same angle of attack, but with the guiding panel, the outlet and the collecting bag being in the bottom of the net section instead of the top (Fig. 2, bottom). Instead of floats, the collecting bag was mounted with a piece of chain to keep it clear of the outlet. 

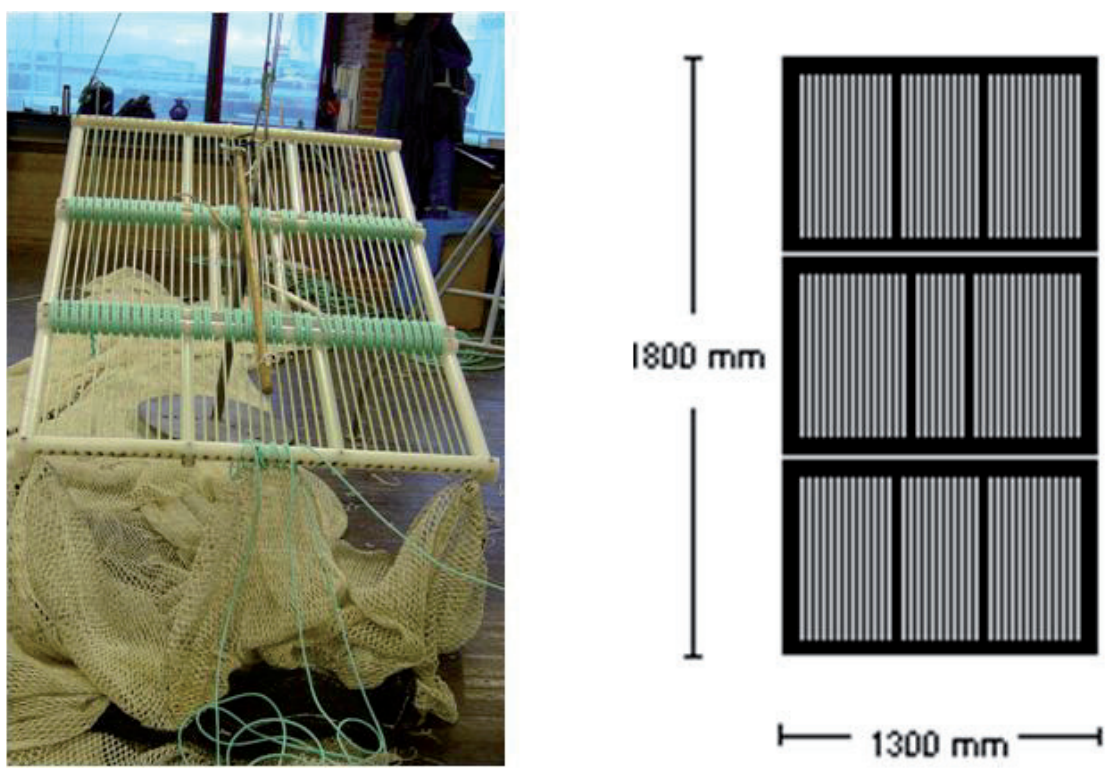

Fig. 1. The grid used for the experimental fishery. The frames of each section are made of $50 \mathrm{~mm}$-thick nylon bars. The grid itself is made of drop-shaped glass fibre bars of $8 \mathrm{~mm}$ width, positioned $23 \mathrm{~mm}$ apart. The two nylon enforcement bars of each grid section are $30 \mathrm{~mm}$ in diameter.

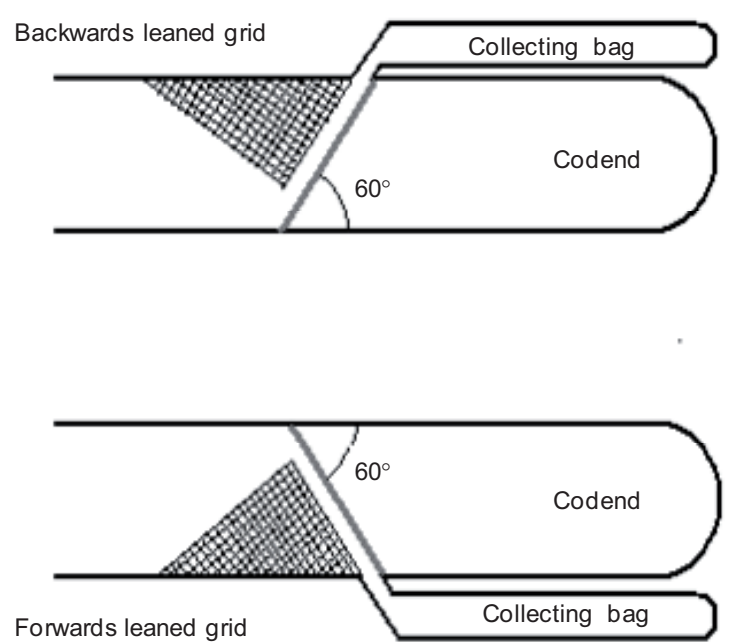

Fig. 2. Drawing of the experimental gear and the two grid orientations, leaning forwards and backwards, tested during the sea trials.

Before testing the experimental gear at sea, the extension piece with the grid and the grid collecting bag was tested in the SINTEF flume tank at the North Sea Science Park in Hirtshals, Denmark (Fig. 3). According to the test performances in the flume tank, minor adjustments were made to the guiding panel position, float placement and chain attachments.

\subsection{Sea trials}

A commercial fishing vessel routinely used for fishing Norway pout in the North Sea was chartered for the experimental fishery: L-530 "Heidi-Malene" is a Danish 35.20 metre

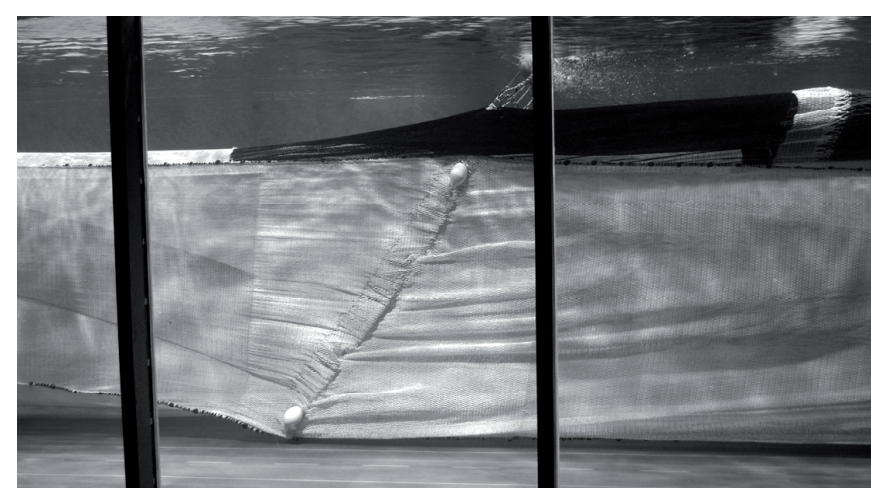

Fig. 3. The grid section in the backwards-leaning configuration in the SINTEF flume tank in Hirtshals.

side trawler with an engine power of $736 \mathrm{~kW}$. Data for the present study was collected during two experimental fishing trials, each of 9 days duration, conducted in the period from November 16 to December 4, 2007.

The areas fished were the traditional Norway pout fishing grounds of Danish fishermen on Fladen Ground in the North Sea and all hauls took place within an area defined by the ICES rectangles 45E9-F1, 46E9-F1 and 47E9-F1, outside the Norway Pout box and without entering the Norwegian zone (Fig. 4). Within these predefined fishing areas, the skipper was allowed to select fishing positions but with the limitation that only pure day or night hauls should be made. To test the durability of the grid and best mimic commercial conditions when hauling the catch, towing times of approx. 8 hours were used. All hauls were conducted with an average towing speed of 3.1 knots. A total of 21 hauls were conducted during the two trials, but only 14 of these were fully valid (Fig. 4 and Table 1). The remaining 7 hauls were omitted from the following analysis due to 
Table 1. Overview of haul details and catch weights from the two experimental trials

\begin{tabular}{|c|c|c|c|c|c|c|c|c|}
\hline Trip & Haul & Date of haul & Time of Day & $\begin{array}{l}\text { Depth } \\
\text { (meters) }\end{array}$ & $\begin{array}{l}\text { Duration } \\
\text { (hours) }\end{array}$ & Grid orientation & $\begin{array}{l}\text { Cod end } \\
\text { (tonnes) }\end{array}$ & $\begin{array}{l}\text { Grid cover } \\
\text { (tonnes) }\end{array}$ \\
\hline 1 & 1 & 16 Nov. & Night & 136 & 8 & Backwards & 11 & 4 \\
\hline 1 & 2 & 17 Nov. & Day & 140 & 8.15 & Backwards & 30 & 5 \\
\hline 1 & 3 & 18 Nov. & Day & 140 & 6.5 & Backwards & 25 & 5 \\
\hline 1 & 4 & 19 Nov. & Day & 144 & 7 & Backwards & 40 & 4 \\
\hline 1 & 5 & 20 Nov. & Day & 131 & 7.15 & Backwards & 25 & 6 \\
\hline 1 & 6 & 20 Nov. & Night & 139 & 8.5 & Backwards & 20 & 1 \\
\hline 2 & 7 & 29 Nov. & Night & 140 & 8 & Forwards & 22 & 3 \\
\hline 2 & 8 & 30 Nov. & Day & 142 & 7 & Forwards & 35 & 5 \\
\hline 2 & 9 & 30 Nov. & Night & 144 & 8.75 & Forwards & 22 & 8 \\
\hline 2 & 10 & 01 Dec. & Day & 138 & 8.25 & Forwards & 32 & 10 \\
\hline 2 & 11 & 01 Dec. & Night & 138 & 9 & Forwards & 21 & 4 \\
\hline 2 & 12 & 03 Dec. & Day & 140 & 5.25 & Backwards & 20 & 2 \\
\hline 2 & 13 & 03 Dec. & Night & 140 & 8 & Backwards & 20 & 2 \\
\hline 2 & 14 & 04 Dec. & Night & 142 & 9.5 & Backwards & 37 & 3 \\
\hline
\end{tabular}

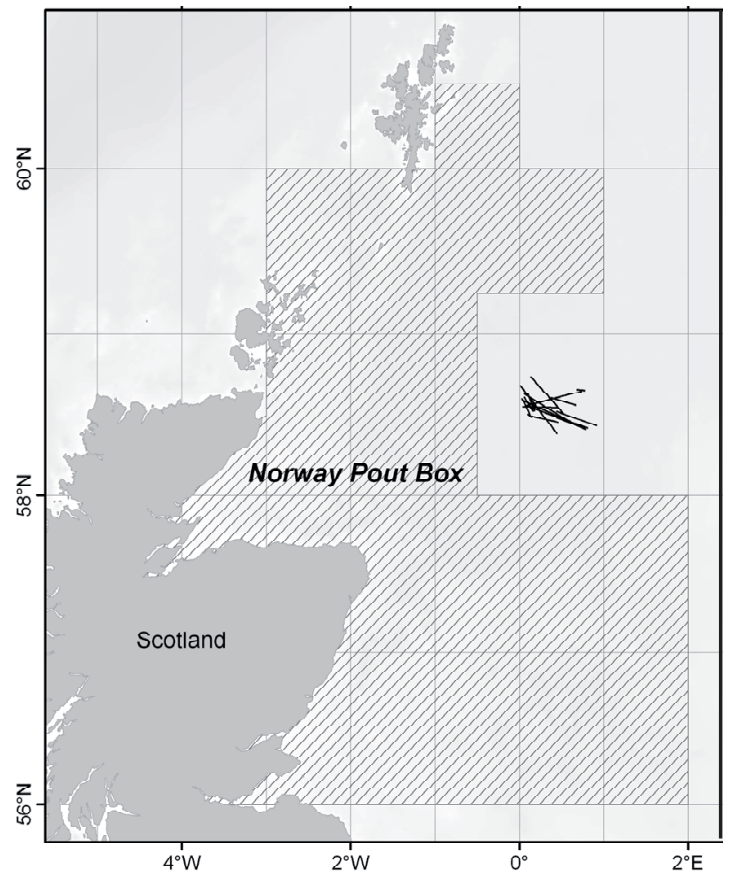

Fig. 4. The northern part of the North Sea, showing the Norway pout box and the 14 fully valid experimental vessel tows.

irregular performance of the trawl and/or the grid (e.g., tearing of netting material or litter blocking the grid).

\subsection{Catch fractions and sampling}

The catch performance of the trawl and the grid system were evaluated by collecting the fish rejected by the grid in a collecting bag ( $22 \mathrm{~mm}$ mesh). The fish passing through the grid, and retained in the cod end ( $22 \mathrm{~mm}$ mesh) were also measured, making it possible to estimate the composition (species, weight and length) of the potential catch entering the trawl, as well as the fraction of fish released (collecting bag) and the fraction of fish actually retained (cod end) (Fig. 2).

The total catch weight of each haul was estimated by the skipper, based on the amount of fish caught in each of the two compartments in the same haul. For all hauls, subsamples were collected from each of the two catch compartments of the experimental gear. Sampling took place during the fish loading process, all sub samples were sorted by species and each fraction then weighed. Because of the very large catches of the experimental fishery (up to $40 \mathrm{t}$ in the cod end and $10 \mathrm{t}$ in the collecting bag) extensive sub sampling was necessary for practical reasons (Table 2). After recording species, weight, and length composition, all sub samples were raised to total catch level by weight factors. Information on each of the catch fractions (grid collecting bag and trawl cod end) was then related to the total (potential) catch of the trawl to provide information on the sorting capability of the grid.

\subsection{Length-based analyses of grid rejection likelihood}

This section describes the modelling and analyses carried out to estimate the length-dependent grid rejection likelihood in relation to grid orientation (forwards/backwards) and time of fishing (day/night). Four species were investigated separately: Norway pout, haddock, whiting and herring.

With the two-compartment experimental design (Fig. 2), it was possible to separate the number of fish being rejected by the grid and collected in the collecting bag $\left(n g_{l}\right)$ from the number of fish passing through the grid to be collected in the 
Table 2. Number of fish measured, and total sub sampling percentages (in brackets) by haul.

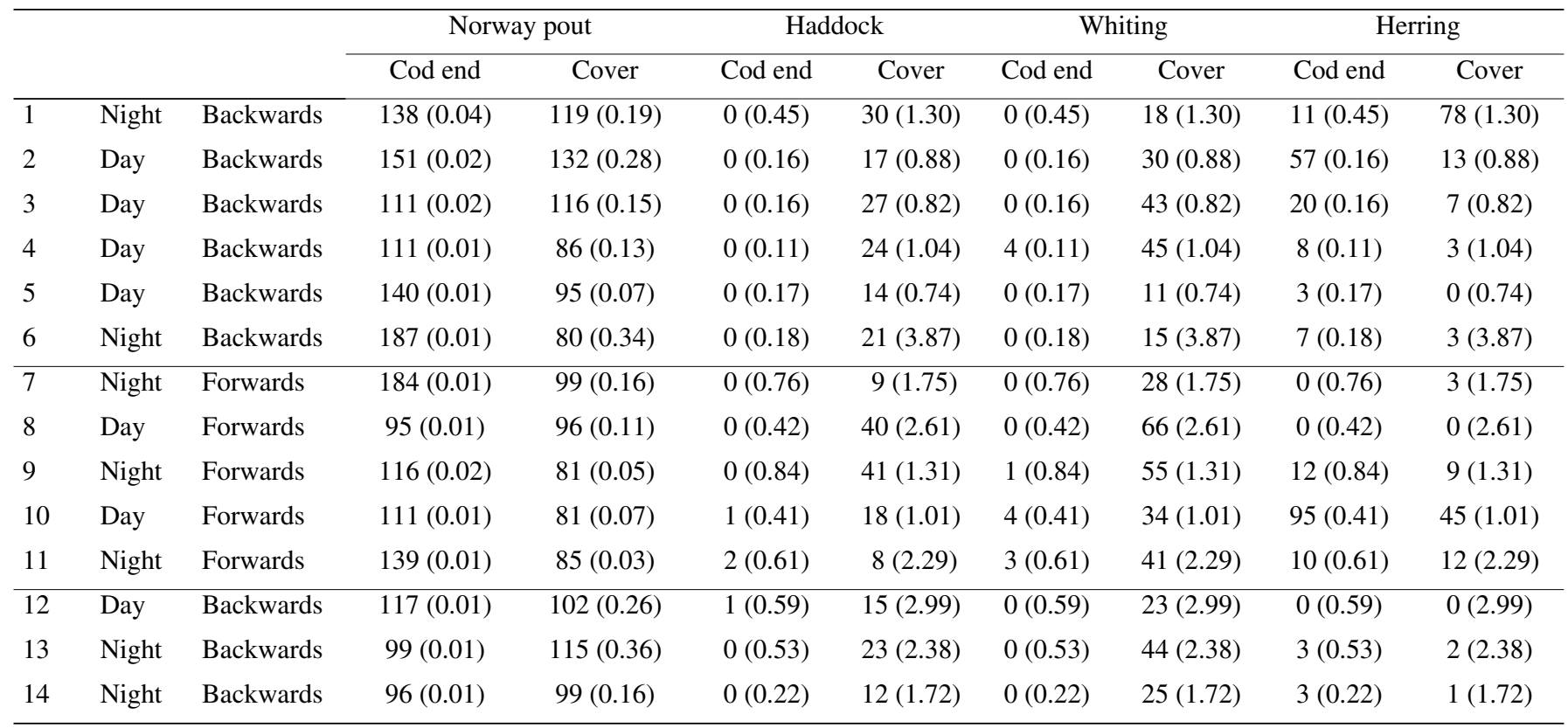

cod end $\left(n c_{l}\right)$ for each haul and each length class $(l)$. Assuming that the fate of each fish is independent from the fate of every other fish, the number of individuals of a specific length class present in the two compartments (collecting bag and cod end) can be modelled by a binominal distribution with lengthdependent probabilities of (i) rejection by the grid $r_{\text {reject }}(l)$ and (ii) being retained in the cod end after passing through the grid $e_{\text {grid }}(l)$. Obviously, only fish up to a certain length (size) will be able to pass through the grid, so individuals above this length will all end up in the grid collecting bag, thus being reflected in a grid rejection likelihood of $100 \%\left(r_{\text {reject }}(l) \approx 1.0\right)$, whereas smaller individuals will have a length-dependent likelihood for passing through the grid when they encounter it $\left(r_{\text {reject }}(l)<1.0\right)$.

The grid rejection likelihood can be expected to depend on the orientation of the fish relative to the grid when they encounter it and might therefore vary with different orientations of the same grid. Further, grid rejection likelihood could potentially be affected by the ability of the fish to visually perceive the grid and might, therefore, differ between day and night fishing. However, for very small fish below some speciesdependent length threshold, it is to be expected that more or less all of them will be "squeezed" through the grid by hydrodynamic pressure, resulting in a close to $0 \%$ grid rejection likelihood $\left(r_{\text {reject }}(l) \approx 0.0\right)$.

For fish between $r_{\text {reject }}(l) \approx 0.0$ and $r_{\text {reject }}(l) \approx 1.0$ the rejection likelihood can be assumed to increase continuously with length towards $100 \%$. A simple function often used for modelling size selectivity in fishing gears, which meets the above outlined properties of the grid rejection likelihood, is the logit model (Wileman et al. 1996). In the present study we chose the logit model, with parameters $L 50_{\text {reject }}$ and $S R_{\text {reject }}$, assuming it was appropriate for modelling the length-dependent grid rejection likelihood of the four species analysed. This assumption is further justified by the successful application of logit models in several other studies of size selectivity in sorting grids (Grimaldo et al. 2008; Sistiaga et al. 2008; Frandsen et al. 2009). On a haul-by-haul basis, the $L 50_{\text {reject }}$ and $S R_{\text {reject }}$ can then, in principle, be estimated by maximizing the corresponding likelihood function for the assumed model. Thus, function 1 below can be minimized, which is equivalent to maximizing this likelihood.

$$
-\sum\left[n g_{l} \times \ln \left(r_{\text {reject }}(l)\right)+n c_{l} \times \ln \left(e_{\text {grid }}(l)\right)\right] .
$$

The summation is over the length classes and the lengthdependent likelihood functions are given by:

$$
\begin{aligned}
& r_{\text {reject }}(l)=\operatorname{logit}\left(l, L 50_{\text {reject }}, S R_{\text {reject }}\right) \\
& e_{\text {grid }}(l)=1.0-r_{\text {reject }}(l)
\end{aligned}
$$

where

$$
\begin{aligned}
& \operatorname{logit}\left(l, L 50_{\text {reject }}, S R_{\text {reject }}\right)= \\
& \frac{\exp \left(\ln (9) \times\left(1-L 50_{\text {reject }}\right) / S R_{\text {reject }}\right)}{1.0+\exp \left(\ln (9) \times\left(1-L 50_{\text {reject }}\right) / S R_{\text {reject }}\right)} .
\end{aligned}
$$

Based on the estimated values for $L 50_{\text {reject }}$ and $S R_{\text {reject }}$, the length-dependent grid rejection likelihood $r_{\text {reject }}(l)$ can be calculated by (2).

Traditionally, the mean length-dependent grid rejection likelihood from a set of hauls would be estimated based on equation (1) to (3), following a two-step procedure considering potential influential factors (fixed effects) like grid orientation and day versus night fishing. The first step would involve estimating parameters $L 50_{\text {reject }}$ and $S R_{\text {reject }}$ of the individual hauls and their covariance matrix. The second step would follow an approach described by Fryer (1991), where both the estimated parameter values and their covariance matrix are used, assuming that the estimated parameter values are observations from 
a multivariate normal distribution. This method considers both the within-haul and between-haul variation in the parameter values and the potential influential factors (fixed effects). However, an initial inspection of the experimental results revealed that the data were not sufficiently robust to be analysed haul by haul. In many hauls there were simply too few fish in the collecting bag or in the cod end (Table 2).

Therefore, we adjusted the traditional two-step approach to accommodate the constraints posed by the form of our data, with extensive sub sampling and narrow length ranges for a number of species. Our approach, which enables estimation of the average length-dependent grid rejection likelihood for each experimental set up separately, is outlined below.

For each species, the data from the different hauls were grouped according to the fixed effects day/night and backwards/ forwards (day grid forwards, night grid forwards, day grid backwards, night grid backwards). The length-dependent grid rejection likelihood was analysed separately for each group, before testing whether they were statistically significant different. Significance was investigated by examining whether there was overlap between the confidence limits for $r_{\text {reject }}(l)$ for the individual length classes. All analyses described were carried out with SELNET computer software (Sistiaga et al. 2010). We estimated what we call the "average" selectivity for the sample of hauls for each group (experimental set up). This approach involved pooling the raised data for all hauls in each experimental set up and applying equation (1) to (3) to the pooled data. According to Millar (1993), if between-haul variation is not of primary interest, fitting the model to pooled data is a reasonable approach for estimating the "average" selectivity for the fishery. Therefore, the sample of experimental hauls for each situation must be a representative sample from that fishery (Millar 1993).

According to Fryer (1991), pooling haul data and then applying the standard methods for estimating parameter standard errors would lead to their underestimation and consequent underestimation of their $95 \%$ confidence intervals. To circumvent the problem of underestimating the confidence limits for the average parameter values, and consequently also of $r_{\text {reject }}(l)$, we used a double bootstrapping method (Efron 1982; Manly 1997) instead of the standard approach. Our approach is similar to the one described in Millar (1993) and to the one applied in Sistiaga et al. (2010), using SELNET to analyse data from a combined selection system involving a grid. It takes both within-haul and between-haul variation into consideration. The hauls for each experimental set up (day grid forwards, night grid forwards, day grid backwards, night grid backwards) were used to define a group of hauls. To account for between-haul variation, an outer bootstrap resample with replacement from the group of hauls was included in the procedure. Within each resampled haul, the data for each length class was bootstrapped in an inner bootstrap with replacement to account for within-haul variation. The inner resampling of the data in each length class were performed prior to the raising of the data, to avoid underestimation of the within-haul variation. Each bootstrap resulted in a "pooled" set of data, which was then analysed according to equation (1) to (3). Thus, each bootstrap run resulted in a set of values for $L 50_{\text {reject }}$ and $S R_{\text {reject }}$. We ran 10000 bootstrap repetitions for each situation using this method. The estimated parameter values for each bootstrap iteration in formula (2) were used to calculate $r_{\text {reject }}(l)$ for each length class $l$, enabling estimation of the "Efron percentile" 95\% confidence limits (Efron 1982; Chernick 2007) for average grid rejection likelihood $r_{\text {reject }}(l)$ for all length classes without having to rely on the delta theorem approximation described by Lehmann (1983).

Besides the length-based analysis described above, we calculated the average length-integrated grid rejection likelihood $p_{\text {reject }}$ in percent for each species for each experimental set up. This was implemented by summing the raised number of fish over length classes $l$ rejected by the grid $n g_{l}$ divided by the raised amount of fish entering $n g_{l}+n c_{l}$ summed over the hauls belonging to each experimental set up (see Fig. 2):

$$
p_{\text {reject }}=100 \times \frac{\Sigma_{l} n g_{l}}{\Sigma_{l}\left[n g_{l}+n c_{l}\right]}
$$

where the summations are made over length classes, thus providing the total raised number of fish.

To separately estimate the uncertainty in $p_{\text {reject }}$ for each species and each experimental set up, considering both the effect of between-haul variation and of the uncertainty related to within-haul variation, we used the double bootstrapping method described above to estimate the "Efron percentile" 95\% confidence limits for $p_{\text {reject }}$.

\section{Results}

\subsection{Grid design and handling}

During the first sea trial with the backwards-leaning grid, handling problems were encountered when hauling the trawl with large catches in the cod end. The main problem was that the top of the grid pointed away from the turning direction of the net drum, which made it difficult to turn the grid on the drum and also inflicted extra strain and frequent tears on the netting material around the corners of the grid. In the forwards-leaning grid configuration, the top of the grid pointed towards the drum when hauling and this configuration almost completely solved the handling problems encountered with the backwards-leaning grid.

\subsection{Resulting catch composition in cod end}

Both grid orientations resulted in very clean cod end catches, with Norway pout constituting an average of $94 \%$ ( $\mathrm{SD}=4.9)$ and $95.7 \%$ ( $\mathrm{SD}=2.6)$ of the total catch weight for hauls with the backwards- and forwards-leaning grids, respectively. Other gadoids (pooled haddock, whiting, cod and saithe) constituted $0.5 \%(\mathrm{SD}=0.8)$ and $1.5 \%(\mathrm{SD}=1.4)$ of the 

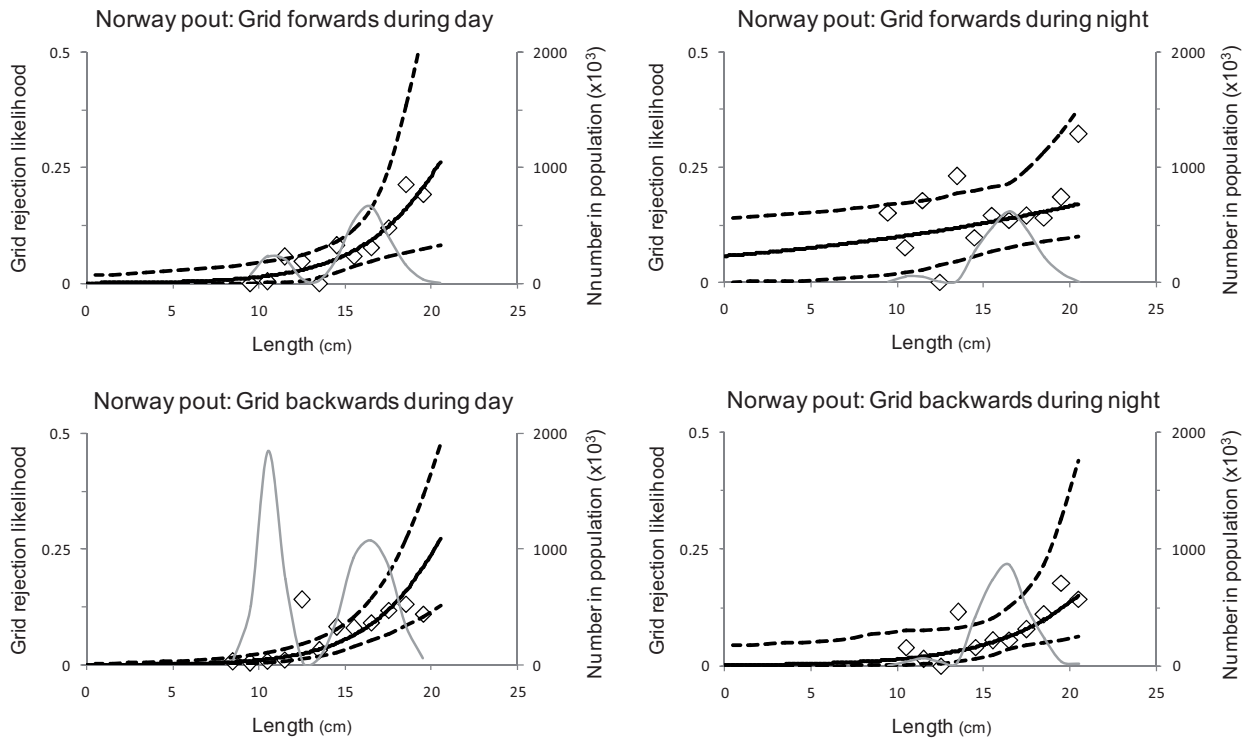

Fig. 5. The estimated proportion of rejected Norway pout (grid rejection likelihood) at length (solid black line) with $95 \%$ confidence intervals (dashed line) and raised number of fish at length in the underlying experimental population (solid grey line).

Table 3. Fish length range $(\mathrm{cm})$, overlap in $95 \%$ confidence intervals.

\begin{tabular}{lcccc}
\hline & Norway pout & Haddock & Whiting & Herring \\
\cline { 2 - 5 } & & Fish length range (cm) & 17 to 44 & full to 32 \\
\hline Day-forwards vs. Night-forwards & 8 to 20 & fo 46 & full \\
Day-backwards vs. Night-backwards & full & full & full & full \\
Day-forwards vs. Day-backwards & full & full & full & full \\
Night-forwards vs. Night-backwards & full & full & full & full \\
\hline
\end{tabular}

Full: $C I$ overlap for all length classes in population.

None: No $C I$ overlap for any length class in population.

Between $x$ and $y$ centimetres: $C I$ overlap for length classes between $x$ and $y$.

total catch weight, herring $3.9 \%(\mathrm{SD}=7.7)$ and $1.8 \%(\mathrm{SD}=2.5)$ and other species (mainly lesser silver smelt Argentina sphyraena, long rough dab Hippoglossoides platessoides and Northern shrimp Pandalus borealis) $1.6 \%(\mathrm{SD}=0.9)$ and $1.0 \%$ $(\mathrm{SD}=0.3)$.

\subsection{Length-based analyses of grid rejection likelihood}

The length-based grid rejection likelihood for Norway pout was very similar across three of the four experimental set ups (day-forwards, day-backwards and night-backwards) with mean values well below 0.1 for fish lengths up to approx. 16$17 \mathrm{~cm}$, after which the rejection likelihood rapidly increased and approached 25\% for Norway pout of approx. $20 \mathrm{~cm}$ (Fig. 5). However, the experimental population contained very few fish above $16-17 \mathrm{~cm}$. This situation was also reflected in the rapidly increasing $95 \%$ confidence intervals for the mean rejection likelihood of the larger length classes, whereas the confidence intervals for the smaller, more frequent, length classes were narrower (Fig. 5). The night-forwards set up deviates somewhat from the other three set ups in that the rejection likelihood was larger for small individuals $(<16 \mathrm{~cm})$ but smaller for large individuals (Fig. 5). A comparison of overlaps in confidence intervals (Table 3) did not validate any significant difference and the full confidence interval overlap with the other three experimental set ups might very well just be a reflection of poor data quality for the night-forwards combination (Table 2).

For length classes in the experimental population with a reasonable number of haddock (length classes above 22$23 \mathrm{~cm}$ ), the mean grid rejection likelihood was consistently high across all four experimental set ups (above 0.8), and the 


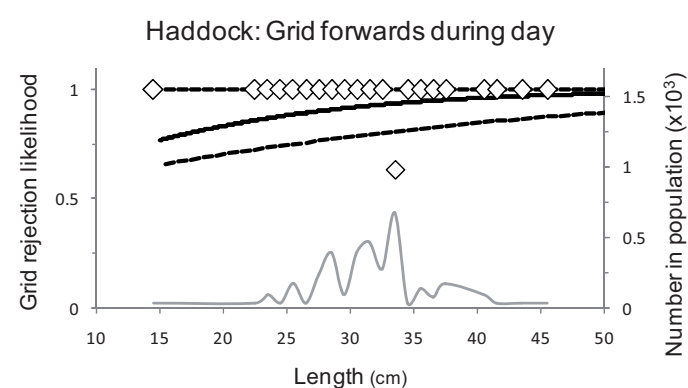

Haddock: Grid backwards during day

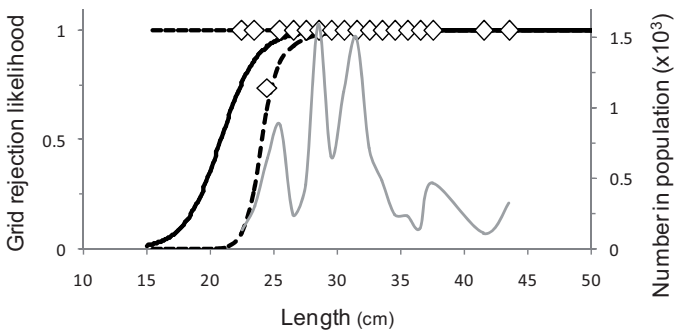

Haddock: Grid forwards during night

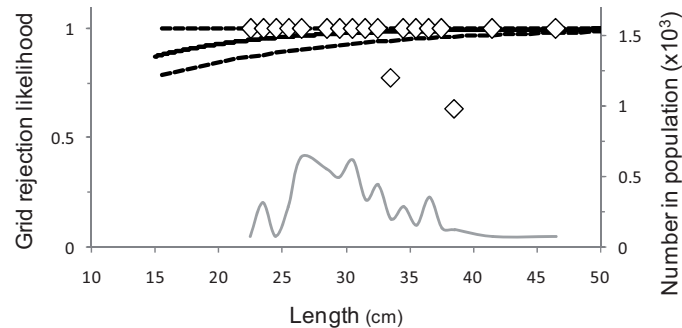

Haddock: Grid backwards during night

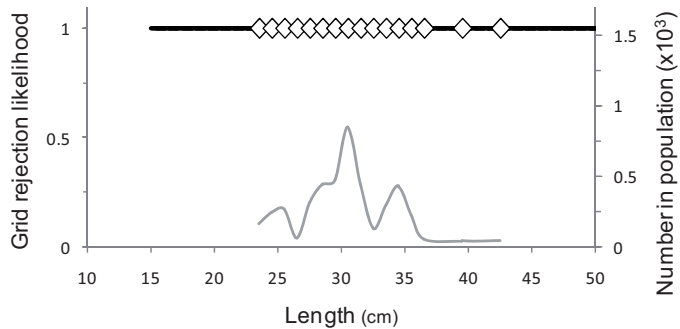

Fig. 6. The estimated fraction of rejected haddock (grid rejection likelihood) at length (solid black line) with $95 \%$ confidence intervals (dashed line) and raised number of fish at length in the underlying experimental population (solid grey line).

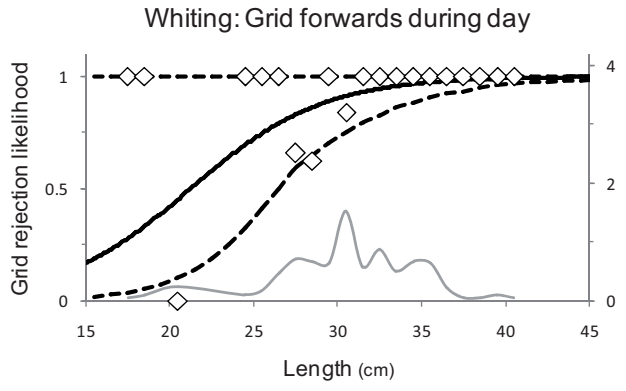

Whiting: Grid backwards during day

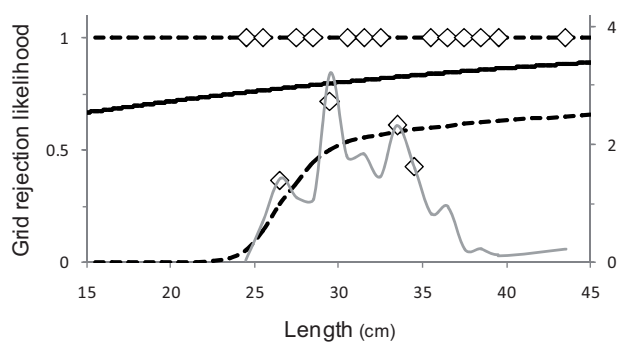

Whiting: Grid forwards during night

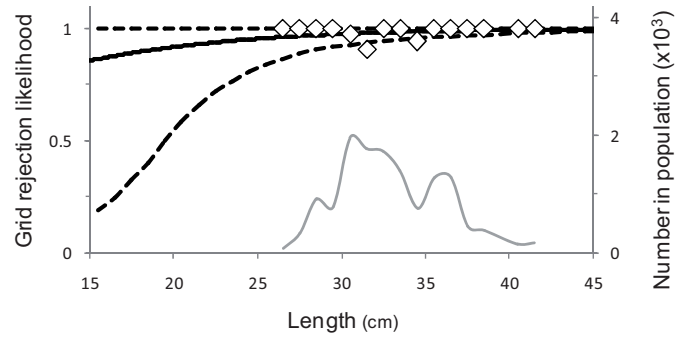

Whiting: Grid backwards during night

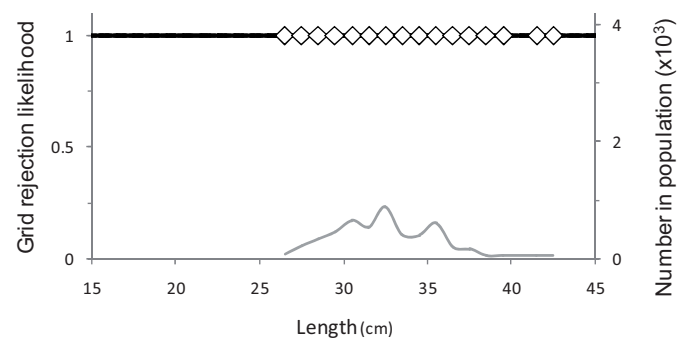

Fig. 7. The estimated fraction of rejected whiting (grid rejection likelihood) at length (solid black line) with $95 \%$ confidence intervals (dashed line) and raised number of fish at length in the underlying experimental population (solid grey line).

confidence intervals are relatively strong (Fig. 6). In the length classes below $22 \mathrm{~cm}$, the estimates were uncertain and confidence intervals large due to scarcity of data.

For whiting of $28 \mathrm{~cm}$ or larger, the average grid rejection likelihood was consistently high (above 0.8 and approaching 1.0 with increasing length) and confidence intervals relatively narrow across three of four experimental set ups (Fig. 7). For the day-backwards configuration, the rejection likelihood was slightly smaller (between 0.75 and 0.90) and confidence intervals substantially higher. For the smaller whiting (below $28 \mathrm{~cm}$ ) of those experimental set ups that had observations in length classes below this size (day-forwards and daybackwards), estimates of rejection likelihood were smaller (decreasing with decreasing length), but the confidence intervals were very large, reflecting the sparse data for these smaller lengths. 


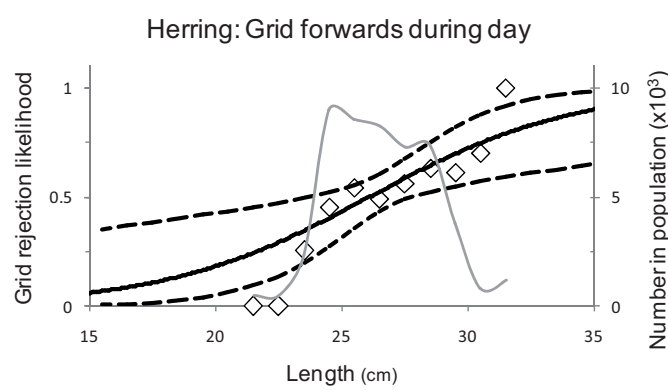

Herring: Grid backwards during day

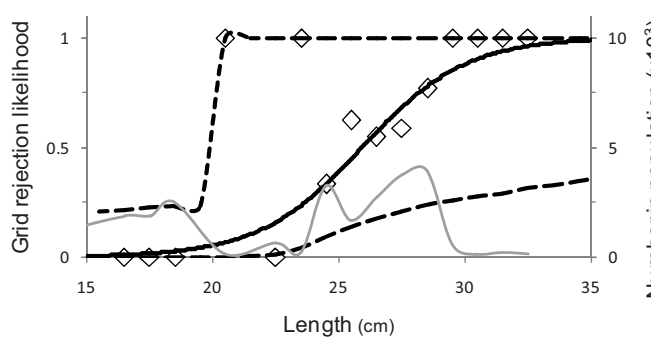

Herring: Grid forwards during night

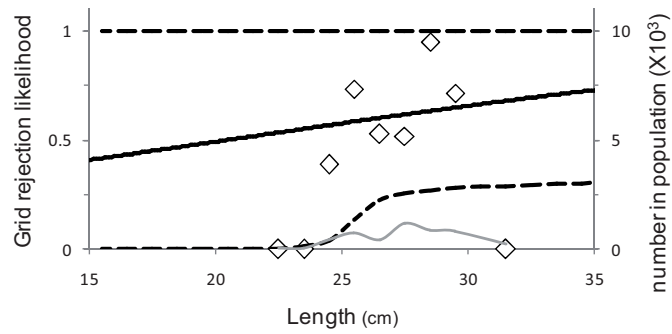

Herring: Grid backward during night

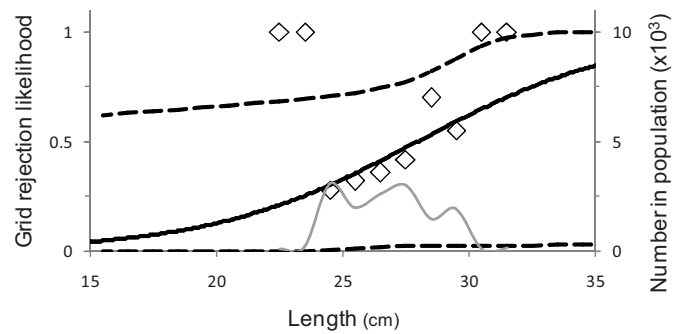

Fig. 8. The estimated fraction of rejected herring (grid rejection likelihood) at length (solid black line) with $95 \%$ confidence intervals (dashed line) and raised number of fish at length in the underlying experimental population (solid grey line).

Table 4. Estimates of length-integrated (total) grid rejection likelihood in percent, $95 \%$ confidence intervals in brackets.

\begin{tabular}{llcccc}
\hline & \multicolumn{1}{c}{ Hauls } & Norway pout & Haddock & Herring & Whiting \\
\hline Day-forwards & 8,10 & $8.0(4.7-13.3)$ & $93.2(81.1-100)$ & $52.8(44.0-60.4)$ & $88.4(70.4-100)$ \\
Night-forwards & $7,9,11$ & $13.7(7.9-22.4)$ & $98.3(94.1-100)$ & $61.5(25.6-100)$ & $98.1(94.3-100)$ \\
Day-backwards & $2,3,4,5,12$ & $5.6(3.3-10.2)$ & $98.4(91.9-100)$ & $39.9(18.4-68.8)$ & $80.9(54.9-100)$ \\
Night-backwards & $1,6,13,14$ & $6.1(3.5-12.1)$ & $100(100-100)$ & $43.0(2.0-75.1)$ & $100(100-100)$ \\
\hline
\end{tabular}

Only the analyses of data from the day-forwards experimental set up allowed any conclusions to be made about the grid rejection likelihood for herring: an $L 50$ estimate close to $27 \mathrm{~cm}$ was found, with a very broad selection range (Fig. 8). For the other experimental set ups the confidence intervals are simply too large to allow any conclusions, even though the mean rejection likelihood estimates from all three experimental set ups are rather similar to the result for the day-forwards situation.

\subsection{Length-integrated grid rejection likelihood}

For three species, the average grid rejection likelihood $p_{\text {reject }}$ of the total number of fish encountering the grid (lengthintegrated grid rejection likelihood) demonstrated rather consistent values across all experimental set ups: Norway pout rejection likelihood was low and ranged from 5.6 to $13.7 \%$ (95\% confidence intervals: $3.3-22.4 \%$ ), haddock rejection likelihood was high and ranged from 93.2 to $100 \%$ (95\% confidence intervals: $81.1-100 \%$ ) and whiting rejection likelihood ranged from 80.9 to $100 \%$ (95\% confidence intervals: 70.4 $100 \%)$. In contrast, the average herring rejection likelihood varied from 43.0 to $61.5 \%$ (95\% confidence intervals: $2.0-100 \%$; Table 4).

\section{Discussion}

The aim of the study was to develop and test new gear designs, capable of minimizing levels of unintended by catch in the Danish Norway pout fishery. This aim has been achieved with the grid experiments and results described. The objectives of improved selectivity, grid handling and durability were tested by designing grids and conducting sea trials in a multidisciplinary approach involving scientific expertise, the commercial fishery, and the gear manufacturing industry. The final grid design demonstrated satisfactory selective properties in terms of the estimated whiting and haddock bycatch reductions (from $88.4-100 \%$ in numbers (CI: 70.4-100\%)). These results are in accordance with two previous experiments with steel sorting grids for the commercial Norway pout trawl fishery in the North Sea (Eigaard and Holst 2004; Kvalsvik et al. 2006), where comparable bycatch reductions were achieved.

\subsection{Grid handling and durability}

The final grid design of cruise 2, with the top of the grid pointing towards the net drum when hauling (Fig. 2, bottom), solved practically all the handling problems encountered on the 
previous cruise without compromising the selectivity of the gear. During the second to last haul in the last cruise, two bars did, however, become dislocated from the frame of the sorting grid, resulting in reduced sorting capacity. This was obviously not satisfactory, but although optimal grid durability was not achieved during the course of this project, the grid performed well enough to convince the fishermen and scientists that the materials and design only need minor modifications to meet the objectives of a durable sorting grid with adequate selective properties and long-term performance.

\subsection{Grid orientation and time of day in relation to grid rejection likelihood}

We hypothesized that shifting the grid orientation, and thereby the outlet and the guiding panel between the top and the bottom of the extension piece, might facilitate the release of bycatch species with top- or bottom-seeking behaviour in trawls. According to the participating fishermen, haddock might be such a species, although no behavioural differences in relation to the two grid orientations were reflected in the lengthbased grid rejection likelihood for haddock or the other bycatch species. It was also hypothesized that the vertical day and night migrations and shifting availability of Gadoids (Michaelsen et al. 1996; Johnsen and Iilende 2007), or the day/night differences in visual response to fishing gear (Wardle 1993) might be utilised in the existing day/night fishing pattern of the Norway pout trawlers to maximize bycatch release. However, no systematic day/night differences of the bycatch species were indicated in the length-based grid rejection likelihoods from our analyses.

In contrast to the analyses of bycatch species, the lengthbased analysis of Norway pout indicated a difference between experimental set ups. The results indicated a larger grid rejection likelihood for smaller Norway pout $(<16 \mathrm{~cm})$ when fishing with a forwards-oriented grid at night. Although non-significant, this difference might reflect a systematic effect of the gridorientation and/or the time of day, which is presumably explained by behavioural and visual aspects of the fish-grid encounter process. This speculation is backed by the fact that the confidence intervals for both night situations are substantially larger than the confidence intervals for the day situations.

Any difference between experimental set ups is only indicative; therefore, although behavioural differences inside a trawl have been documented to result in species-specific trawl selectivity for a number of fish species (e.g., Krag et al. 2009; Sala and Lucchetti 2010), the results from this study instead tend to support the idea that grid sorting was almost purely size dependent for Norway pout, haddock, whiting and herring. This size-specific selectivity hypothesis is also supported by two other studies that were not able to document any substantial behavioural differences in experiments explicitly focused on separating Norway pout from other Gadoids in industrial trawling in the North Sea (Wileman and Main 1994; Kvalsvik et al. 2006).

\subsection{Length-integrated grid rejection likelihood}

With length-integrated average grid rejection likelihoods across all four experimental set ups between 80.9 and $100 \%$ for the main bycatch species and between 5.6 and $13.7 \%$ for the target species, the tested grid appears to serve its purpose well, irrespective of grid orientation and time of day. In a commercial context, the difference between a 5.6\% (day-backwards) and a $13.7 \%$ (night-forwards) loss of target species makes a substantial difference. Although this difference cannot be said to be significant based on the confidence intervals, it cannot be ruled out - due to the somewhat limited data set - that there is a systematic difference between these sets of fishing conditions, which it would be worthwhile exploring further.

\subsection{Temporal and spatial selectivity}

Clearly, if the grid developed in this study was introduced in the fishery, it would be capable of increasing the sustainability of the small-meshed Norway pout fishery in the North Sea above the level achievable with the technical measures presently in use. However, smaller whiting and haddock $(<20 \mathrm{~cm})$ are only present in relatively low numbers in the catches, underlining the main experimental result of substantial bycatch reduction (Figs. 6 and 7), but increasing the uncertainty about the length-based grid rejection results and about the magnitude of the estimated bycatch reduction. One could argue that if there had been a higher number of small haddock and whiting present during the trials, the reductions obtained would have been substantially smaller because smaller fish pass through the grid to a large extent. Although this is reasonable to assume, the argument that the variation in availability of haddock and whiting across seasons and areas (Zheng et al. 2001; Rindorf et al. 2010) might affect bycatch reduction levels also points in a positive direction. It indicates that by combining the grid with a spatio-temporally optimised and controlled fishing effort (to focus the fishing effort in areas and seasons with a minimum overlap in size distribution of target and bycatch species) it would be possible to further improve the grid sorting.

\subsection{Perspectives for future fisheries}

Unintended bycatch is broadly recognized as a main ecological side-effect of fishing (Tserpes et al. 2006) and, according to Gislason (2006), technical measures in terms of gear modifications are key requirements of an ecosystem approach to fisheries management (EAFM). In this context, the grid developed in this study offers an obvious opportunity to move the Norway pout fishery towards a more EAFM. Use of the grid leads to substantial bycatch reductions, as documented in the present paper. It has no unintended ecological side effects, only limited handling and durability problems, and only inflicts moderate economic losses for fishermen, as judged by the percentage of target species lost. Presumeably this loss will to some degree be compensated by fishing power increases from 
technological development, as demonstrated for other demersal trawl fisheries (Eigaard 2009, Eigaard and Munch-Petersen 2011), but a relative loss of catch efficiency as a consequence of a grid implementation seems inevitable. Although the achieved results are promising, there is still room for improvement in the grid's sorting capabilities. This could be pursued through technical development of e.g., guiding panels or bar design, but also through the use of a more defined spatio-temporal fishing effort allocation in combination with the grid (possibly with different bar distances in different areas and seasons) to optimize the selectivity and sustainability of the fishery.

Acknowledgements. We wish to thank The Danish Directorate for Food, Fisheries and Agri Business for funding the work presented here through the European Union FIFG-program. We also wish to thank the Danish Fishermen's Association and the crews and teams of the "Heidi Malene", Cosmos trawl, SINTEF Flume tank, Meche Trawl, Scanmar Esbjerg and Scanmar Norway for their participation and cooperation in the project. The assistance from the anonymous reviewers and the editor is also much appreciated.

\section{References}

Chernick M.R., 2007, Bootstrap Methods: A guide for practitioners and researchers, second edition. Wiley series in probability and statistics. Wiley, New York.

Efron B., 1982, The jackknife, the bootstrap and other resampling plans. SIAM Monograph No. 38, CBSM-NSF.

Eigaard O., Holst R., 2004, The effective selectivity of a composite gear for industrial fishing: a sorting grid in combination with a square mesh window. Fish. Res. 68, 99-112.

Eigaard O.R., 2009, A bottom-up approach to technological development and its management implications in a commercial fishery. ICES J. Mar. Sci. 66, 916-927.

Eigaard O.R., Munch-Petersen S., 2010, Influence of fleet renewal and trawl development on landings per unit effort of the Danish northern shrimp (Pandalus borealis) fishery. ICES J. Mar. Sci. 68, 26-31.

EU, 2011, The Common Fisheries Policy, A User's Guide [online]. Availablefromhttp://www.ec.europa.eu/fisheries/documentation/ publications/pcp2008_en.pdf [accessed August 5, 2011].

Fryer R.J., 1991, A model of between-haul variation in selectivity. ICES J. Mar. Sci. 48, 281-290.

Frandsen R.P., Holst R., Madsen N. 2009, Evaluation of three levels of selective devices relevant to management of the Danish KattegatSkagerrak Nephrops fishery. Fish. Res. 97, 243-252.

Gislason H., 2006, The requirements of an ecosystem approach to fisheries management. In: Motos L., Wilson D.C. (Eds). The knowledge base for fisheries management. Developments in Aquaculture and Fisheries Science, Elsevier, pp. 307-328.

Greenstreet S.P.R., Rogers S.I., 2000, Identifying key nature conservation issues. In: Kaiser M. J., de Groot S.B. (Eds). Effects of fishing on non-target species and habitats. Blackwell Science, Oxford pp. 217-234.

Grimaldo E., Larsen R.B., 2005, The cosmos grid: A new design for reducing by-catch in the Nordic shrimp fishery. Fish. Res. 76, 187-197.
Grimaldo E., Sistiaga M., Larsen R.B., 2008, Evaluation of codends with sorting grids, exit windows, and diamond meshes: Size selection and fish behaviour. Fish. Res. 91, 271-280.

ICES, 2007, ICES WGNSSK Report including stock Annex for Norway pout. ICES CM 2007\ACFM:18 and 30.

ICES, 2011, ICES WGNSSK Report, including Stock Annex for Norway pout [online]. Available from http://www.ices.dk/ workinggroups/ViewWorkingGroup.aspx?ID=3 [accessed 5 . Aug. 2011].

Isaksen B., Valdemarsen J.W., Larsen R.B., Karlsen L., 1992, Reductions of fish bycatch in shrimp trawl using rigid separator grid in the aft belly. Fish. Res. 13, 335-352.

Johnsen E., Iilende T., 2007, Factors affecting the diel variation in commercial CPUE of Namibian hake - can new information improve standard survey estimates? Fish. Res. 88, 70-79.

Krag L.A., Holst R., Madsen N., 2009, The vertical separation of fish in the aft end of a demersal trawl. ICES J. Mar. Sci. 66, 772-777.

Kvalsvik K., Huse I., Misund O.A., Gamst K., 2006, Grid selection in the North Sea trawl fishery for Norway pout: Efficient size selection reduces bycatch. Fish. Res. 77, 248-263.

Lambert G., Nielsen J.R., Larsen L., Sparholt H., 2009, Maturity and Growth population dynamics of Norway pout (Trisopterus esmarkii) in the North Sea, Skagerrak and Kattegat. ICES J. Mar. Sci. 66, 1899-1914.

Lehmann E.L., 1983, Theory of Point Estimation. New York, John Wiley and Sons.

Lewinson R.L., Crowder L.B., Read A.J., Freeman S.A., 2004, Understanding impacts of fisheries bycatch on marine mega fauna. Trends Ecol. Evol. 19, 598-604.

Loaec H., Morandeau F., Meillat M., Davies P., 2006, Engineering development of flexible selectivity grids for Nephrops. Fish. Res. 79, 210-218.

Madsen N., Hansen K., 2001, Danish experiments with a grid system tested in the North Sea shrimp fishery. Fish. Res. 52, 203-216.

Manly B.F.J., 1997, Randomization, Bootstrap and Monte Carlo methods in biology - Texts in statistical science. Chapman \& Hall.

Michaelsen K., Godø O.R., Fernö A., 1996, Diel variation in the catchability of gadoids and its influence on the reliability of abundance indices. ICES J. Mar. Sci. 53, 389-395.

Millar R.B., 1993, Incorporation of between-haul variation using bootstrapping and nonparametric estimation of selection curves. Fish. Bull. 91, 564.

Riedel R., DeAlteris J., 1995, Factors affecting hydrodynamic performance of the Nordmøre Grate system: a bycatch reduction device used in the Gulf of Maine shrimp fishery. Fish. Res. 24, 181-198.

Rindorf A., Andersen N.G., Vinther M., 2010, Spatial differences in natural mortality of North Sea gadoids. ICES CM 2010/C:18

Sala A., Lucchetti A., 2010. The effect of mesh configuration and codend circumference on selectivity in the Mediterranean trawl Nephrops fishery. Fish. Res. 103, 63-72.

Sistiaga M., Grimaldo E., Larsen R.B., 2008, Size selectivity patterns in the North-East Arctic cod and haddock fishery with sorting grids of 55, 60, 70 and $80 \mathrm{~mm}$. Fish. Res. 93, 195-203.

Sistiaga M., Herrmann B., Grimaldo E., Larsen R.B., 2010, Assessment of dual selection in grid based selectivity systems. Fish. Res. 105, 187-199.

Sparholt H., Larsen L.I., Nielsen J.R., 2002a, Verification of multispecies interactions in the North Sea by trawl survey data on Norway pout (Trisopterus esmarkii). ICES J. Mar. Sci. 59, 1270-1275. 
Sparholt H., Larse L.I., Nielse J.R., 2002b, Non-predation natural mortality of Norway pout (Trisopterus esmarkii) in the North Sea. ICES J. Mar. Sci. 59, 1276-1284.

Tserpes G., Peristerakis P., Nielsen J.R., 2006, Ecological side-effects of fishing from the fisheries management perspective. In: Motos L., Wilson D.C. (Eds.). The knowledge base for fisheries management. Developments in Aquaculture and Fisheries Science, Elsevier, pp. 267-294.
Wardle C.S., 1993, Fish behaviour and fishing gear. In: Pitcher T.J. (ed.), The behaviour of Teleost fishes. Fish and Fisheries Series 7 , 2nd edn., Chapman and Hall, London, pp. 609-644.

Wileman D.A., Main J., 1994, Attempts to develop a species selective trawl for fishing pout. ICES CM 1994/B: 94.

Zheng X., Pierce G.J., Reid D.G., 2001, Spatial patterns of whiting abundance in Scottish waters and relationships with environmental variables. Fish. Res. 50, 259-270. 